\title{
COMMENT
}

\section{Long-term changes in diel vertical migration behavior: more ups and downs}

\author{
Sifford Pearre, $\mathrm{Jr}^{*}$ \\ Dept. of Oceanography, Dalhousie University, Halifax, Nova Scotia B3H 4J1, Canada
}

Hays (1995) and Hays et al. (1996) analyzed Continuous Plankton Recorder (CPR) records to determine if diel vertical migrations (DVMs) of North Sea copepods had changed in response to changes in predator (chiefly herring) abundances between 1958 and 1996. While they did find such a correlation, their analysis has been challenged by Hirst \& Batten (1998), primarily on 2 grounds: (1) Hays (1995) and Hays et al. (1996) did not properly assess the dark period, mistakenly including some light periods as dark and vice-versa, due to seasonally changing day-lengths; (2) they used an index of diel migration, their 'DVM ${ }_{\text {index }}$ ' (changed in the second paper to ' $N / D_{\text {index }}$ '), which was sensitive to sample size. Hirst \& Batten (1998) proposed their own, which they confusingly termed 'DVM' (the usual abbreviation for the phenomenon of diel vertical migration itself - I will refer to the index as ' $\mathrm{HB}$ '), designed to remedy the sample-size sensitivity in $\mathrm{N} / \mathrm{D}_{\text {index, }}$ the Hays index. In fact, as a ratio measure, $\mathrm{N} / \mathrm{D}_{\text {index }}$ should not be sensitive to abundances, but only becomes so because of the ' 1 ' added to allow logarithmic transformation when abundances are zero. In general, CPR sample sizes are too large for any biases to be noticeable. The variability at very small sample sizes could be reduced by use of a constant small relative to the counting unit, say 0.001 , instead of 1 . If this were done in the example calculation provided by Hirst \& Batten, then when $\mathrm{n}_{\text {night }}=20$ and $\mathrm{n}_{\text {day }}=10$, an $\mathrm{N} / \mathrm{D}_{\text {index }}$ of 1.9999 would be estimated (instead of 1.909 ), while with $n_{\text {night }}=2$ and $n_{\text {day }}=1$, an $N / D_{\text {index }}$ of 1.9990 would be estimated (instead of 1.5 ).

Hirst \& Batten (1998) go on to test a different hypothesis: that it is the availability of food (as water color) which governs DVM behavior (Hardy \& Gunther 1935). Though not quite significant, correlation of their index $\mathrm{HB}$ with water color was indeed better than with herring abundance, as would be expected from results from other studies (e.g. Huntley \& Brooks 1982, Johnsen \& Jakobsen 1987, Flik \& Ringelberg 1993).

·E-mail: pearre@is.dal.ca
However, it remains reasonable that effects on migration of predator abundance should be noticeable at least in a long time-series (e.g. see Gliwicz 1986). It would be interesting to investigate the combined effect of both factors.

However, neither N/D index (a ratio) nor HB (a proportion) can be considered normally distributed, so that, strictly, neither should be used in ordinary parametric statistical analyses. Thus, probabilities based on associations of either index with environmental variables, while useful guides, can only be considered approximate. A better approximation could be achieved by using a 'normalizing' transformation, such as the arcsine, on HB (Sokal \& Rohlf 1981), or by using a nonparametric test.

Other, potentially more serious problems come from the sampling methodology itself. First, variations in abundance at a single, near-surface depth could easily be the result of patchiness or other artifacts (Roe 1974). Only strong repeatability (consistently finding higher abundances at night) renders this a plausible method of DVM investigation. As the number of days covered by a sampling program is decreased, eventually there would be no way to identify the signals as true DVM. The depth sampled is usually about $6.5 \mathrm{~m}$ (Hays \& Warner 1993), not really a 'surface' sample, and it is seldom clear whether the copepods were feeding at this depth, merely passing through, or engaging in 'reverse' DVMs from the surface layer (Roe 1974, Hays et al. 1996). Even assuming that the copepods do spend the dark hours within the phytoplankton maximum, as the depth of this varies through the year, the perceived migration regime must vary with it.

Second, and more importantly, it is also known that many zooplankton species undertake other patterns of diel excursions. A common pattern, known at least from the time of Michael (1911), involves 'midnight sinking', in which the population comes to the surface near dusk, then descends again and may reappear at the surface later ('dawn rise') before making its daytime descent. This bimodal activity cycle actually 
means that total migration activity is greater than in a simple unimodal daily migration, but grouping all 'dark' and all 'daylight' samples reduces the apparent night and day abundance differences, making migration appear less. In his influential 1951 review, Cushing stated that midnight sinking was an element of the most general migration pattern, and noted that it was often reported in Calanus finmarchicus, the copepod discussed by Hays (1995) and by Hirst \& Batten (1998). Midnight sinking was noted in $82 \%$ of records of western North Atlantic spring zooplankton DVM by Ashjian et al. (1998). The extreme of this pattern is 'twilight' migration, in which the migrators only approach the surface near dawn and dusk. The day and night mean depths, and hence the day and night CPR catches, could be equal. According to Atherton (1979). Temora longicornis, one of the copepods discussed by Hays et al. (1996), is a twilight migrator, and Mackas \& Bohrer (1976) found that the 2 twilight depth minima reported by Atherton corresponded to feeding maxima. In summer samples, Harding et al. (1986) reported that $T$. longicornis was near the surface only at dusk, though late-night upswimming was observed in directional plankton traps. Potentially, CPR analysis could be a powerful method for investigating such alternative rhythms, but the lumping of 'day' and 'night' samples must be abandoned.

Third, and perhaps most seriously: it was in Calanus finmarchicus vertical distributions that Gauld (1953) first inferred satiation-driven descent, which has been confirmed in this species by Simard et al. (1985) and Durbin et al. (1995). Since then it has become apparent that not only copepods but many other aquatic organisms, including cladocerans (Angeli et al. 1995), euphausiids (Simard et al. 1986, Gibbons 1993), chaetognaths (Pearre 1973, Stuart \& Verheye 1991, Gibbons 1994), and fish (Narver 1970) can use satiation as a cue to descend rapidly, but asynchronously (Pearre 1979). Usually this means that more migration is occurring than is revealed by stratified sampling, and significant migration could occur with no discernable changes in mean population depth (e.g. Gauld 1953, Pearre 1973, Gibbons 1994). Note that this violates the criteria of Ashjian et al. (1998) for identifying DVM.

As well as Temora longicornis and adult (C5-C6) Calanus finmarchicus (discussed above), Hays et al. (1996) examined the CPR records of 5 copepod groupings: Calanus sp. C1-C4, Centropages typicus, Centropages hamatus, Acartia clausii, and a combined category of Paracalanus sp. and Pseudocalanus spp. (which can have different DVM patterns) as 'Para-Pseudocalanus'. Various studies have touched upon satiationregulated descent in most of these species. Although Zagorodnyaya (1975) reported strong nocturnal DVM in Pseudocalanus elongatus in the Black Sea, high pro- portions of individuals in the deepest layer (100 to $150 \mathrm{~m}$ ) contained food at 02:00 and 03:00 h. This is far too deep for phytoplankton grazing, and must indicate that there was also rapid, satiation-based early descent not detectable from the net samples. Harding et al. (1986) found that descending Pseudocalanus caught in bidirectional traps contained significantly more food than those caught swimming up. Mackas \& Bohrer (1976), in their pioneering study of the use of gut chlorophyll fluorescence to trace migration and feeding, reported that both Pseudocalanus and Centropages typicus had satiation-driven descent. Tang et al. (1994) reported that Paracalanus spp. had limited DVM in Hong Kong Harbor, but the early evening presence of chlorophyll in the guts of the deepestcaught animals argues for satiation-driven migration in this genus as well. Gut-contents analysis is at present our only means to detect such movements.

In any species in which individuals descend when satiated, it is not easy to interpret population migrations from stratified sampling results, and especially not from samples from a single depth, such as those from a CPR. Simard et al. (1986) inferred satiationmediated descent of the euphausiid Thysanoessa raschii from the digestive state of near-surface samples alone, but it is doubtful whether such analyses could be performed on CPR material, which becomes distorted from pressure on the rolls. However, if zooplankters migrate upwards to feed, it could turn out that the effect of predators-visual (e.g. herring) or non-visual (e.g. medusae)-lies more in influencing the timing and synchronization of DVM than its range or intensity (e.g. Dawidowicz 1993).

Whatever the indices, the types of analyses performed by Hays (1995), Hays et al. (1996), and Hirst \& Batten (1998) on DVM, or by Beare \& McKenzie (1999) on population changes, can be extremely useful. They direct our attention to possible environmental interactions, and even a suggestive relationship with any environmental variable is of great interest (Beare \& McKenzie 1999). The wonderful long CPR records are unique and invaluable for identifying population trends and anomalies and for addressing preliminary questions. However, as Hirst \& Batten advise, we should be cautious about depending on only that type of data to find definitive answers to questions of diel migrations.

\section{LITERATURE CITED}

Angeli N, Pinel-Alloul B, Balvay G, Ménard I (1995) Diel patterns of feeding and vertical migration in daphnids and diaptomids during the clear water phase in Lake Geneva (France). Hydrobiologia 300/301:163-184

Ashjian CJ, Smith SL, Flagg CN, Wilson C (1998) Patterns and occurrence of diel vertical migration of zooplankton bio- 
mass in the Mid-Atlantic Bight described by an acoustic Doppler current profiler. Cont Shelf Res 18:831-858

Atherton WC (1979) An annual study of the vertical migration patterns of zooplankton in Bedford Basin, Nova Scotia MSc thesis, Dalhousie Univ

Beare DJ, McKenzie E (1999) Connecting ecological and physical time-series: the potential role of changing seasonality. Mar Ecol Prog Ser 178:307-309

Cushing DH (1951) The vertical migration of planktonic Crustacea. Biol Rev 26:158-192

Dawidowicz P (1993) Diel vertical migration in Chaoborus flavicans: population patterns vs. individual tracks. Arch Hydrobiol Beih Ergebn Limnol 39:19-28

Durbin EG, Campbell RG, Gilman SL, Durbin AG (1995) Diel feeding behavior and ingestion rate in the copepod Calanus finmarchicus in the southern Gulf of Maine during late spring. Cont Shelf Res 15:539-570

Flik BJG, Ringelberg J (1993) Influence of food availability on the initiation of diel vertical migration (DVM) in Lake Maarsseveen. Arch Hydrobiol Beih Ergebn Limnol 39: $57-65$

Gauld DT (1953) Diurnal variations in the grazing of planktonic copepods. J Mar Biol Assoc UK 31:461-474

Gibbons MJ (1993) Vertical migration and feeding of Euphausia lucens at two $72 \mathrm{~h}$ stations in the southern Benguela upwelling region. Mar Biol 116:257-268

Gibbons MJ (1994) Diel vertical migration and feeding of Sagitta friderici and Sagitta tasmanica in the southern Benguela upwelling region, with a comment on the structure of the guild of primary carnivores. Mar Ecol Prog Ser 111:225-240

Gliwicz ZM (1986) Predation and the evolution of vertical migration. Nature 320:746-748

Harding GC, Vass WP, Hargrave BT, Pearre S Jr (1986) Diel vertical movements and feeding activity of zooplankton in St. Georges Bay, N.S., using net tows and a newly developed passive trap. Can J Fish Aquat Sci 43:952-967

Hardy AC, Gunther ER (1935) The plankton of the South Georgia whaling ground and adjacent waters, 1926-27. 'Discovery' Rep 11:1-456

Hays GC (1995) Zooplankton avoidance activity. Nature 376: 650

Hays GC, Warner AJ (1993) Consistency of towing speed and sampling depth for the Continuous Plankton Recorder. J Mar Biol Assoc UK 73:967-970

Hays GC, Warner AJ, Lefevre D (1996) Long-term changes in the diel vertical migration behaviour of zooplankton. Mar Ecol Prog Ser 141:149-159
Hirst AG, Batten SD (1998) Long-term changes in the diel vertical migration behaviour of Calanus finmarchicus in the North Sea are unrelated to fish predation. Mar Ecol Prog Ser 171:307-310

Huntley M, Brooks ER (1982) Effects of age and food availability on diel vertical migration of Calanus pacificus. Mar Biol 71:23-31

Johnsen GH, Jakobsen PH (1987) The effect of food linitation on vertical migration in Daphnia longispina. Limnol Oceanogr 32:873-880

Mackas D, Bohrer R (1976) Fluorescence analysis of zooplankton gut contents and an investigation of diel feeding patterns. J Exp Mar Biol Ecol 25:77-85

Michael EL (1911) Classification and vertical distribution of the Chaetognatha of the San Diego region. Univ Calif Publ Zool 8:21-186

Narver DW (1970) Diel vertical movements and feeding of underyearling sockeye salmon and the limnetic zooplankton in Babine Lake, British Columbia. J Fish Res Board Can 27:281-316

Pearre S Jr (1973) Vertical migration and feeding in Sagitta elegans Verrill. Ecol 54:300-314

Pearre S Jr (1979) Problems of detection and interpretation of vertical migration. J Plankton Res 1:29-44

Roe HSJ (1974) Observations on the diurnal vertical migrations of an oceanic animal community. Mar Biol 28:99-113

Simard Y, Lacroix G, Legendre L (1985) In situ twilight grazing rhythm during diel vertical migrations of a scattering layer of Calanus finmarchicus. Limnol Oceanogr 30: $598-606$

Simard Y, Lacroix G, Legendre L (1986) Diel vertical migrations and nocturnal feeding of a dense coastal krill scattering layer (Thysanoessa raschi and Meganyctiphanes norvegica) in stratified surface waters. Mar Biol 91:93-105

Sokal RR, Rohlf FJ (1981) Biometry: the principles and practice of statistics in biological research. WH Freeman \& Co, San Francisco

Stuart V, Verheye HM (1991) Diel migration and feeding patterns of the chaetognath, Sagitta friderici, off the west coast of South Africa. J Mar Res 49:493-515

Tang KW, Chen QC, Wong CK (1994) Diel vertical migration and gut pigment rhythm of Paracalanus parvus, P. crassirostris, Acartia erythraea, and Eucalanus subcrassus (Copepoda, Calanoida) in Tolo Harbour, Hong Kong. Hydrobiologia 292/293:389-396

Zagorodnyaya YuA (1975) Vertical migration and daily ration of the copepod Pseudocalanus elongatus (Boeck) in the Black Sea. Biol Morya, Kiev 33:11-18 